\title{
Nuevas Especies Anthurium de Oaxaca
}

$$
\text { Por Eizi Matuda }
$$

Anthurium nizandensis Matuda, sp. nov.

Foliorum petiolus subquadrangulus, antice late canaliculatus, 6-8 cms. longus, geniculo brevi instructus; lamina subcoriacea, oblongo ovata, apice acuta, basim versus cuneatim angustata, 3-3.5 dm. longa, medio 1.5-1.8 dm. lata, margine leviter undulata, costa crassa, subtetragona, supra medio carinata; nervis lateralibus primariis utrinque 7-8 patentibus, subparallelis, juxta costam decurrentibus; pedunculus quam folia multo longior, crassus subcylindricus $45-40 \mathrm{~cm}$. longus. Spatha lanceolata, acuminata crassiuscula, basi amplexa, brunnea. Spadix spatham multo superans, sessilis, rubiginosus, 12-14 cm. longus, 9-11 $\mathrm{mm}$. crassus.

México: Oaxaca; Nizanda, Istmo de Tehuantepec; enero 6 de 1959.

Thomas MacDougall, sin número - Tipo en el Herbario Nacional del Instituto de Biología, U. N. A. M.

Fig. 1.

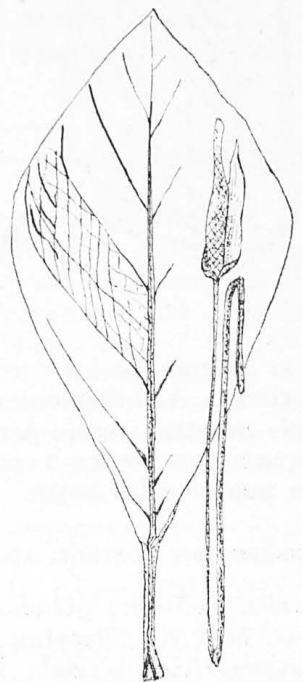

ANTHURIUM NIZANDENSIS

Matuda.

Matuda E. 1959. Nuevas especies Anthurium de Oaxaca. Boletín de la Sociedad Botánica de México 24: $35-38$. 
Planta acaule; pecíolos subcuadrangulares, al frente acanalados, de 6-8 cm. de largo, con el genículo grueso y corto; lámina subcoriácea, oblongo-val, ápice agudo, base cuneada, de 3-3.5 dm. de largo por 1.5-1.8 de ancho, margen levemente ondulada, costilla gruesa, subtetrágona, en el haz subcarinada: nervadura laterales primarias 7-8, gruesas, algo paralelas, extendidas hacia el margen; pedúnculos largos, subcilíndricos, de $45-50 \mathrm{~cm}$. de largo, espata lanceolada, acuminada, la base amplexicaule, de color castaño obscuro, casi erguida, o extendida, no reflejada, de $8-9 \mathrm{~cm}$. de largo por 2-8 de ancho en la base; espádice sésil, pardo moreno, de $12-14 \mathrm{~cm}$. de largo por 9-11 mm. de grosor.

Fig. 2.

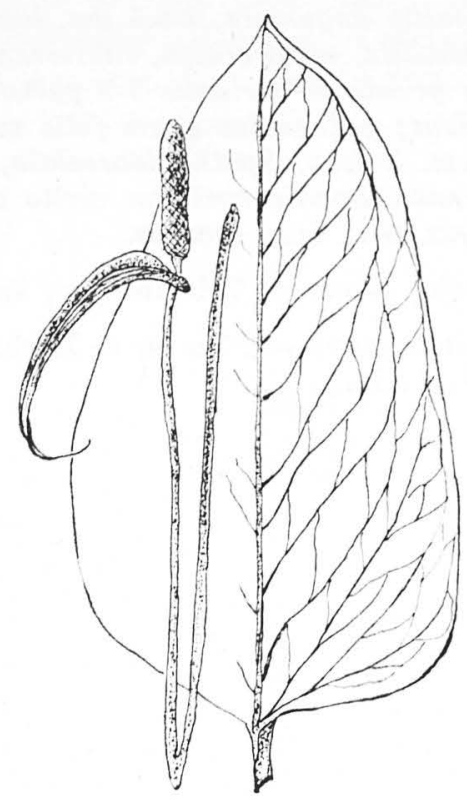

ANTHURIUM SUBOVATUM Matuda

Esta especie pertenece a la Sección Pachyneurium Schott, por la forma de la hoja, y es muy próxima a A. Lindmanianum Engl., especie del sur de Brasil, pero se distingue nuestra especie por las hojas más chicas, por las nervaduras primarias que apenas tienen $3 \mathrm{~cm}$. de distancia y por los pedúnculos largos que exceden mucho a las hojas.

\section{Anthurium subovatum Matuda, sp. nov.}

Ut videtur terrestris, acaulis. Foliorum petiolus teres supra canaliculatus, geniculo brevi instructus, basi vix dilatatus brevi vaginatus, 14-16 cm. longus; lamina coriacea, supra virida nitidula, subtus pallidior, oblongo elliptica, apice acuta, basi obtusa vel truncata, 20-24 cm. longa, 8-14 
$\mathrm{cm}$. lata, nervo collectivo antimarginali a margine 4-6 $\mathrm{mm}$. remoto, nervis lateralibus primariis utrinque circ. 8-10, angulo circ. $40^{\circ}$ a costa abeuntibus arcuatim adscendentibus. Pedunculus petiolis duplo longior, $34 \mathrm{~cm}$. longus. Spatha lanceolata, longe cuspidata, $9 \mathrm{~cm}$. longa, $1.2 \mathrm{~cm}$. lata, ex viridi brunnescens. Spadix stipite circ. $4 \mathrm{~mm}$. longo suffultus, cylindricus, purpureo brunnescens, $5 \mathrm{~cm}$. longus $5 \mathrm{~mm}$. crasssus.

México: Oaxaca, Carretera entre Cerro Pelón y Yatla, a 1900 m., enero 12 de 1959, Thomas MacDougall 406.-Tipo en el Herbario Nacional del Instituto de Biología, U. N. A. M.

Planta terrestre y acaule. Pecíolos cilíndricos, acanalados en el frente, genículos cortos, en la base poco dilatados y muy cortamente envainantes, de 14-16 cm. de largo; lámina coriácea, el haz verde brillante, algo pálido amarillento en el envés, oblongo ovada, ápice agudo, la base obtusa o truncada; de 20-24 cm. de largo, por 8-14 ancho; nervaduras laterales primarias 10-12, con ángulo de $40^{\circ}$ con la central; nervio colectivo de 4-6 mm. distante del margen; pedúnculos casi dos veces la longitud de los pecíolos, de $34-38 \mathrm{~cm}$. de largo; espata lanceolada, largamente cuspidada, de $9 \mathrm{~cm}$. de largo por 1.2 de ancho, verdoso-castaño; espádice con estípite de $4 \mathrm{~mm}$ de largo, cilíndrico, purpúreo obscuro, de $5 \mathrm{~cm}$. de largo por $5 \mathrm{~mm}$. de grosor.

Esta planta por la forma de la hoja y la flor, pertenece a la Sección Xialophyllium Schott, y es muy cercana a $A$. Tuerckheimii y $A$. Nakamurae, pero se separa de éstas por su pedúnculo largo, y la espata larga y cuspidada.

Anthurium cerropelonense Matuda, sp. nov.

Ut dicitur terrestris, caudiculo brevi, crasso. Foliorum petiolus basi incrassatus breviter vaginatus, quam lamina longior, geniculo crassiusculo $11.5 \mathrm{~cm}$. longo instructus; lamina subcoriacea, late cordato ovata, 30 $\mathrm{cm}$. longa $20 \mathrm{~cm}$. lata, apice breviter cuspidato acuta, basi cordata, lobis posticis semiorbiculatis, $1 \mathrm{~cm}$. longis $6 \mathrm{~cm}$. latis, sinu semianguste campaniformi, supra lucida viridis, subtus pallida; nervis lateralibus primariis loborum posticorum 4, recurvatis, nervis primariis antico 5, adscendentibus tenerrimis subarcuatis, prope marginem in nervum colectivum conjunctis, venulis prominulis dense reticulatis; pedunculus crassus, quam petiolus previter, $20 \mathrm{~cm}$. longus; spatha cartilaginea ovalilanceolata apice cuspidato-acuminata, basi fere amplectens, quam spadi 1/4 brevitor, erecta, intus purpurascens, dorso viridis tenuiter multinervia; spadix breviter stipitatus, cylindricus, $10 \mathrm{~cm}$. longus, $1 \mathrm{~cm}$. crassus, rosaseus, demum purpuréus.

México: Oaxaca, Carretera entre Cerro Pelón y Yatla, a $2600 \mathrm{~m} .$, enero 12 de 1959, Thomas MacDougall No. 405.-Tipo en el Herbario Nacional del Instituto de Biología, U. N. A. M. 
Fig. 3.

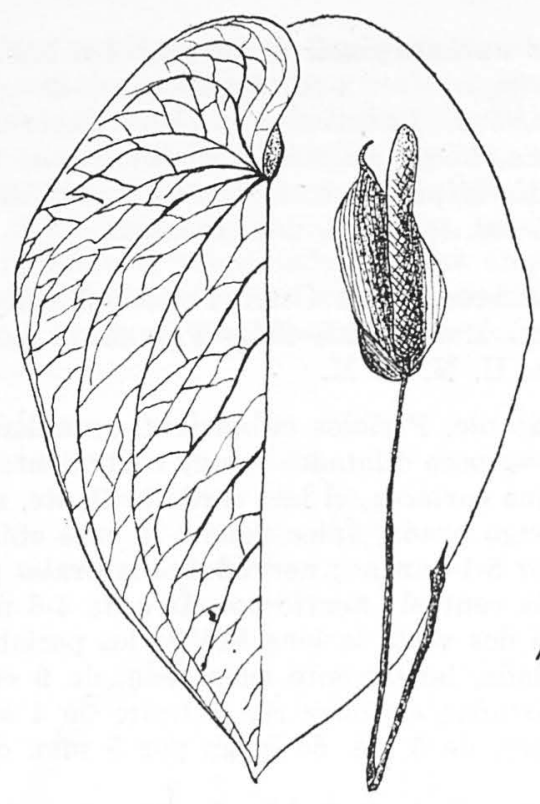

ANTHURIUM CERRO. PELONENSE Matuda

Pecíolos con genículos gruesos de $1.5 \mathrm{~mm}$. de largo, en la base dilatados y muy cortamente envainantes, más largos que la lámina; lámina subcoriácea, anchamente ovada, de $30 \mathrm{~cm}$. de largo por 20 de ancho, el ápice agudo, cortamente cuspidado, la base cordada, las aurículas posteriores semiorbiculadas, de $7 \mathrm{~cm}$. de largo por 6 de ancho, a veces sobrepuestas, seno angosto campaniforme, el haz verde brillante, el envés pálido amarillento; nervaduras primarias laterales basales 4, recurvadas en las aurículas, en el lóbulo anterior 5, todas ascendentes, se reunen con nervio colectivo dejando 8-10 $\mathrm{mm}$. de espacio con el margen; las nervaduras secundarias delgadas y densamente reticuladas; pedúnculo relativamente grueso de $20 \mathrm{~cm}$. de largo; espata cartillanginosa, lanceolado oval, ápice acuminado cuspidado, la base amplexicaule, poco más corta que el espádice, erguida, al interior purpúrea, al exterior verdosa, con numerosas nervaduras paralelas; espádice cortamente est:pitado cilíndrico, de $10 \mathrm{~cm}$. de largo por 1 de grosor, de color morado purpúreo.

Por la forma de hoja y espata y el color del espádice, esta especie pertenece a la Sección Colomystrium Schott y es muy próxima a A. montanum, pero se distingue fácilmente nuestra especie, por tener el seno no profundo y la espata ancha y cuspidada. No hay similares en las especies mexicanas. 